\title{
Estimation of retired mobile phones generation in China: A comparative study on methodology
}

\author{
Bo Li ${ }^{a}$, Jianxin Yang ${ }^{\mathrm{a}, *}$, Bin Lu ${ }^{\mathrm{a}}$, Xiaolong Song ${ }^{\mathrm{b}}$ \\ a State Key Laboratory of Urban and Regional Ecology, Research Center for Eco-Environmental Sciences, Chinese Academy of Sciences, Shuangqing Road 18, Haidian District, \\ Beijing 100085, China \\ b Shanghai Cooperative Centre for WEEE Recycling, Shanghai Second Polytechnic University, Jinhai Road 2360, Pudong District, Shanghai 201209, China
}

\section{A R T I C L E I N F O}

\section{Article history:}

Received 7 June 2014

Accepted 11 September 2014

Available online 1 October 2014

\section{Keywords:}

Mobile phone

Retired

Generation

Estimation

WEEE

Waste management

\begin{abstract}
A B S T R A C T
Due to the rapid development of economy and technology, China has the biggest production and possession of mobile phones around the world. In general, mobile phones have relatively short life time because the majority of users replace their mobile phones frequently. Retired mobile phones represent the most valuable electrical and electronic equipment (EEE) in the main waste stream because of such characteristics as large quantity, high reuse/recovery value and fast replacement frequency. Consequently, the huge amount of retired mobile phones in China calls for a sustainable management system.

The generation estimation can provide fundamental information to construct the sustainable management system of retired mobile phones and other waste electrical and electronic equipment (WEEE). However, the reliable estimation result is difficult to get and verify. The priority aim of this paper is to provide proper estimation approach for the generation of retired mobile phones in China, by comparing some relevant methods. The results show that the sales\&new method is in the highest priority in estimation of the retired mobile phones. The result of sales\&new method shows that there are 47.92 million mobile phones retired in 2002, and it reached to 739.98 million in China in 2012. It presents an increasing tendency with some fluctuations clearly.

Furthermore, some discussions on methodology, such as the selection of improper approach and error in the input data, are also conducted in order to improve generation estimation of retired mobile phones and other WEEE.
\end{abstract}

() 2014 Elsevier Ltd. All rights reserved.

\section{Introduction}

The mobile phone has become the most ubiquitous electronic product. At the end of 2013, it was estimated that there were 6.66 billion mobile phone subscribers globally (ITU, 2014), of which 1.23 billion were in China (MIIT, 2014). Meanwhile, the rapid technology innovation with better functions and models impelled the customers to change mobile phones more and more frequently, which leads to the short lifetime of mobile phones and rapid generation of retired mobile phones. Due to the relatively small sizes, retired mobile phones can be easily stored and forgotten or thrown out with the municipal waste (Canning, 2006; Darby and Obara, 2005). And many retired mobile phones are not disposed in the proper way (through reuse or recycling) but stockpiled (Geyer and Doctori Blass, 2009; Nokia, 2008; Wagner, 2009).

\footnotetext{
* Corresponding author. Tel./fax: +86 1062849802.

E-mail address: yangjx@rcees.ac.cn (J. Yang).
}

In many regions and countries, the retired mobile phones are classified as waste electrical and electronic equipment (WEEE) (Li et al., 2006; European Commission, 2012), which is one of the priority waste streams. Main reasons for the concern of WEEE are very fast growth rate of the waste stream and its complex composition with a potential negative effect on environment and human health (European Commission, 2012).WEEE stream can be divided into large WEEE (e.g. refrigerators, washing machines, etc.) and small WEEE (e.g. mobile phones, digital cameras, music players, etc.) (Martinho et al., 2012; Sole et al., 2012). The retired mobile phones is a kind of typical small WEEE with the characteristics such as big amount, high reuse/recovery value and fast replacing frequency (Ongondo and Williams, 2011a; Polak and Drapalova, 2012). The retired mobile phones seem to have a minor share on the amount of WEEE generated. However, considering the huge amount of the mobile phones subscriptions around the world, their contribution to total environmental impacts of WEEE should not be neglected (Wu et al., 2008; Nnorom and Osibanjo, 2009).

Legislations and policies have been enacted to manage the retired mobile phones, such as the European WEEE Directive 
(European Commission, 2012) or California's Cell Phone Recycling Act (CPRA) (California State Congress, 2004), which are usually based on the principle of extended producer responsibility (EPR) (Ongondo and Williams, 2011b; Silveira and Chang, 2010). However, in China, mobile phones have not been included in the WEEE management framework (Chi et al., 2011; Matsuto, 2014).

Estimation of waste quantities is the fundamental work to waste management. However, it is difficult to make valid estimation and to prove it. The reliable estimation can provide fundamental information to construct a sustainable management system of retired mobile phones, but there is still no such achievement in China. The goal of this contribution aims to make reliable estimation of retired mobile phones in China. In addition, some discussions on methodology, such as the common source of uncertainties in the previous studies are also conducted in detail in order to improve generation estimation of WEEE.

\section{Literature review}

There are various approaches used to estimate the generation of WEEE or retired mobile phones in particular all around the world (Araujo et al., 2012; Chung et al., 2010, 2011; Dwivedy and Mittal, 2010a,b; Gutierrez et al., 2010; Polak and Drapalova, 2012; Steubing et al., 2010; Walk, 2009; Yang et al., 2008; Yoshida et al., 2009). These approaches can be classified into the following models: input-output model, time-series model, factor model, econometrics analysis and direct waste analysis.

The input-output model is so far the most promising and frequently used with multiple model variations, which has been applied to estimate WEEE generation in many regional and country studies by quantitatively evaluates the sources, pathways and final sinks of material flows. In this model, information on product lifespan and a delay (equivalent to the lifespan) for electrical and electronic equipment (EEE) to become WEEE are always needed to complete the estimation. This model can develop to other approaches such as market supply method (including classic market supply method, market supply A method and Stanford method), consumption and use approach, time-step method, MFA method, use-phase analysis, ICER model and Carnegie Mellon method.

The time-series model, in which "time" is used as a predictor variable, involves the use of historical data and their distribution to extrapolate future waste trends. It can be also applied to fill in the gap of past unknown years from available datasets. The advantages of time-series model are its flexibility and limited demand of data. In many cases, only data for two variables are needed: time and the past pattern of the key variable to be predicted. Waste data measured at any kind of meaningful intervals, such as annual, monthly or even daily waste data can be used in such estimations. On the other hand, the simple model leads to the neglect of the other potentially influential explanatory variables, so the changes in the future cannot be reflected appropriately (Wang et al., 2013). The time-series model including several approaches, such as curve estimation techniques, exponential smooth, linear extrapolation, trend analysis and periodic approaches (Walk, 2004). This category of approaches usually used to make the generation estimations of municipal solid waste in various temporal and spatial scales (Chung, 2010; Matsuto and Tanaka, 1993; Navarro-Esbri et al., 2002), some case studies on WEEE are also can be found (Masui, 2005; Huisman et al., 2007).

The factor model uses factors such as socio-economic and other explanatory variables to explain and predict waste arising, which aims at making predictions on waste quantities and unveiling hypothetical causal relationships between factors for the prediction of waste generation at the same time (Walk, 2004). The explanatory variables include population, household size, residency type, age groups, employment, income level, electricity consumption, tipping fees, education, culture, geography, climate and so on (Chung, 2010). The weight of the factors may be different in the various case studies. It is the least explored method due to complex factors interaction and high uncertainty in time-series. There are several previous studies focused on the generation estimations of the WEEE can be found (Chung et al., 2011; Saphores et al., 2009).

The econometrics analysis makes generation estimations of the waste based on the econometrics indicators, such as gross domestic product (GDP) (Nordic Council of Ministers, 2009). The econometrics analysis can be regarded as the combination of time-series model and factor model. Some Nordic nations, such as Denmark (Danish Environmental Protection Agency, 2006) and Norway (Statistic Norway, 2004), make generation estimations of WEEE using this model.

The direct waste analysis uses e-waste figures obtained from collection channels, treatment facilities and disposal sites. It is seldom mentioned to estimate quantities of WEEE disposed of, practical records of WEEE receipts in all local waste facilities are the source of information that can be obtained by field determination at major end-disposal facilities (Chung, 2011). Hong Kong SAR government used this model to estimate e-waste disposal figures of the city (Environment Bureau, 2010).

Sales, possession, lifetime and distribution are usually essential information for input-output model. Historical collected (generation) amount, saturation factor, substitution effect, influential factors, econometrics indicators are needed by other models. The correspondence between the data and approaches are stated in Table 1. Some approaches have other designation in different literatures, they are also listed in Table 1 to avoid confusion.

Focusing on the retired mobile phones, there are several trials to estimate the generation with various approaches. The approaches are mainly extended from input-output model. For instance, Fishbein (2002) estimated number of cell phones retired per year in the US using the classic market supply method, Eugster et al. (2007) estimated the retired mobile phones generation in China in the same way; Gao et al. (2010) and Polak and Drapalova (2012) forecasted the generation of end-of-life mobile phones in China and Czech Republic using the market supply A method, respectively; Liao and Zhang (2012) made a comparative study based on the estimation results of discarded mobile phones in China using the classic market supply method, time-step method and approximation, respectively. With MFA method, Yu et al. (2010) and Jang and Kim (2010) estimated the generation of retired mobile phones in China and Korea, respectively. Moreover, Osibanjo et al. (2008) modelled the waste generation by the telecom sector in Nigeria by regression analysis.

The life cycle of mobile phones can be divided into six phases, which can be defined as raw materials production, manufacture, circulate/distribute, consume/use, retire/reuse/stockpile and endof-life. Various data needed for the estimations lie in the certain phase, the concerned phases of all the approaches mentioned above are illustrated in Fig. 1.

There are several problems that can influence the accuracy and credibility of the estimation lie in the previous studies. For example, appropriate primary data are difficult to get and secure, some estimations are even based on secondary data (Chung, 2011). At the meantime, the lifetime of a certain kind of EEE are changed rapidly with the improving technology and between different countries and regions.

\section{Methodology}

\subsection{Definition}

The retired mobile phones were defined as the mobile phones that stop the service in the mobile tele-communication networks. 
Table 1

Data demands for various approaches.

\begin{tabular}{|c|c|c|c|c|c|c|c|c|c|}
\hline & Other designation & $\begin{array}{l}\text { Sales } \\
\text { (production, } \\
\text { import and } \\
\text { export) }\end{array}$ & $\begin{array}{l}\text { Lifetime } \\
\text { distribution }\end{array}$ & Possession & $\begin{array}{l}\text { Historical } \\
\text { collected/ } \\
\text { generation } \\
\text { amount }\end{array}$ & $\begin{array}{l}\text { Saturation } \\
\text { factor }\end{array}$ & $\begin{array}{l}\text { Substitution } \\
\text { effect }\end{array}$ & $\begin{array}{l}\text { Influential } \\
\text { factors }\end{array}$ & $\begin{array}{l}\text { Econometric } \\
\text { indicators }\end{array}$ \\
\hline $\begin{array}{l}\text { Market } \\
\text { supply } \\
\text { method }\end{array}$ & $\begin{array}{l}\text { Classic market supply } \\
\text { method/sales/simple } \\
\text { delay }\end{array}$ & $\sqrt{ }$ & $\sqrt{ }$ & & & & & & \\
\hline $\begin{array}{l}\text { Market } \\
\text { supply A } \\
\text { method }\end{array}$ & Distribution delay & $\sqrt{ }$ & $\sqrt{ }$ & & & & & & \\
\hline $\begin{array}{l}\text { Stanford } \\
\text { method }\end{array}$ & & $\sqrt{ }$ & $\sqrt{ }$ & & & & & & \\
\hline $\begin{array}{l}\text { Carnegie } \\
\text { Mellon } \\
\text { method }\end{array}$ & & $\sqrt{ }$ & $\sqrt{ }$ & & & & & & \\
\hline $\begin{array}{l}\text { Consumption } \\
\text { and use } \\
\text { approach }\end{array}$ & $\begin{array}{l}\text { Approximation/ } \\
\text { estimate formula/batch } \\
\text { leaching }\end{array}$ & & $\sqrt{ }$ & $\sqrt{ }$ & & & & & \\
\hline $\begin{array}{l}\text { Time-step } \\
\text { method }\end{array}$ & & $\sqrt{ }$ & & $\sqrt{ }$ & $\sqrt{ }$ & & & & \\
\hline MFA method & & $\sqrt{ }$ & & $\sqrt{ }$ & & & & & \\
\hline ICER model & & $\sqrt{ }$ & & & & $\sqrt{ }$ & & & \\
\hline $\begin{array}{l}\text { Use-phase } \\
\text { analysis }\end{array}$ & & & $\sqrt{ }$ & $\sqrt{ }$ & & & $\sqrt{ }$ & & \\
\hline $\begin{array}{c}\text { Time-series } \\
\text { model }\end{array}$ & Projection & & & & $\sqrt{ }$ & & & & \\
\hline Factor model & & & & & $\sqrt{ }$ & & & $\sqrt{ }$ & \\
\hline $\begin{array}{c}\text { Econometric } \\
\text { analysis }\end{array}$ & & & & & & & & & $\sqrt{ }$ \\
\hline $\begin{array}{l}\text { Direct waste } \\
\text { analysis }\end{array}$ & $\begin{array}{l}\text { Waste facility record } \\
\text { compilation/disposal } \\
\text { related analysis }\end{array}$ & & & & $\sqrt{ }$ & & & & \\
\hline
\end{tabular}

As a matter of fact, most of these retired mobile phones were stored in people household and will enter the waste stream later. That means retired mobile phones present the potential mobile phones to be recycled.

\subsection{Methods}

To get the accurate result, the estimations based on three approaches are made in this paper. These approaches are called market supply A method, consumption and use approach and sales\&new method, respectively. All the chosen approaches have been used to estimate the generation of retired mobile phones in the previous studies (Polak and Drapalova, 2012; Yu et al., 2010; Gao et al., 2010; Liao and Zhang, 2012).

\subsubsection{The market supply A method}

The market supply A method is also called "distribution delay method" in some literatures (Polak and Drapalova, 2012). This approach requires two types of input data, the probable lifetime distribution and sales data of mobile phones in certain countries and regions. The basic formula for estimating the generation of retired mobile phones can be defined:

$R_{t}=\sum_{i} S_{t-i} \cdot P_{i}$

where $R_{t}$ is the generation of retired mobile phones in the year $t ; S_{t}$ is the sales data of mobile phones in the year $t ; P_{i}$ is the probability of retired mobile phones arising in the year $t$ with a product lifetime of $i$.

The annual sales data can be calculated with the following formula:

$S_{t}=P_{t}-E_{t}+I_{t}$

where $P_{t}$ is the domestic production of mobile phones in the year $t$; $E_{t}$ is the amount of export in the year $t ; I_{t}$ is the amount of import in the year $t$.

\subsubsection{The consumption and use approach}

The consumption and use approach is also called "approximation", "estimate formula" or "batch leaching" in some literatures (Polak and Drapalova, 2012). This approach requires two types of input data, the possession and probable lifetime of mobile phones in certain countries and regions. The basic formula for estimating the generation of retired mobile phones can be defined:

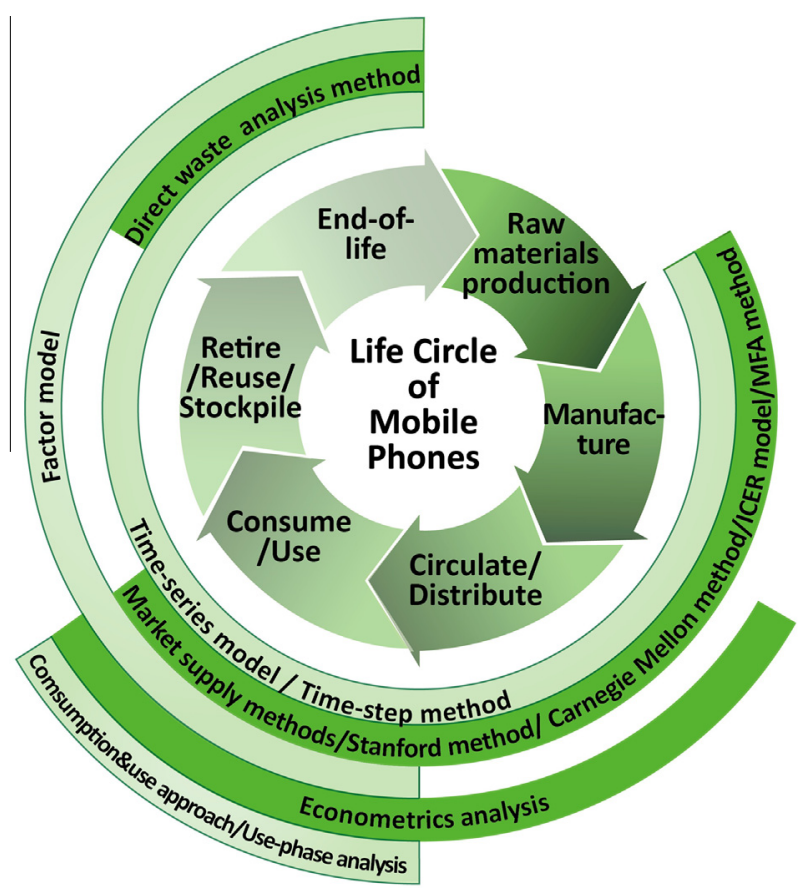

Fig. 1. The concerned phases in the life cycle of mobile phones of various approaches. 
$Q_{t}=H_{t} / n$

where $H_{t}$ is the domestic possession of mobile phones in the year $t$, which is approximately equivalent to the amount of subscribers of the year $t\left(U_{t}\right) ; n$ is the lifetime of mobile phones.

\subsubsection{The sales\&new method}

The sales\&new method is a new approach based on the principle of material conservation, while in some previous studies it was called the MFA method (Jang and Kim, 2010; Yu et al., 2010). We specialize the MFA method to estimate the generation of retired mobile phones and name it as sales\&new method. The basic equation of this approach can be defined:

$\Delta M=\sum F_{\text {in }}-\sum F_{\text {out }}$

where $\Delta M$ is the change in the material stock in a process; $F_{\text {in }}$ is the sum of flows entering a process; $F_{\text {out }}$ is the sum of flows leaving a process.

In the reality, majority of the users need a mobile phone for each subscriber, so we can treat the amount of subscribers in use as a stock of mobile phones demanded with certain volume; the amount of new subscribers in certain period represents the change of the stock volume at the same time, which equivalent to $\Delta M$; the sales data represents the sum of flows entering the mobile phones stock, equivalent to $\sum F_{\text {in }} ; \sum F_{\text {out }}$, the sum of flows leaving the mobile phones stock can be treated as the amount of retired mobile phones.

The sales\&new method can be defined as the following formula:

$W_{t}=S_{t}-N_{t}$

where $W_{t}$ is the generation of retired mobile phones in the year $t ; S_{t}$ is the sales data of mobile phones in the year $t ; N_{t}$ is the amount of new mobile phone subscribers in the year $t$.

\subsection{Data sources}

\subsubsection{Sales}

The sales data on mobile phone subscribers in China are calculated with the equation above using the related data that are available from the series of Electronic Information Industry Statistics Yearbook of China by Ministry of Industry and Information Technology (MIIT, 2003, 2004, 2005, 2006, 2007, 2008, 2009, 2010, 2011, 2012, 2013). This sales data including all the brand new mobile phones with a "Network access permission mark" authenticated by MIIT and unique IMEI (International Mobile Equipment Identification) by GMSA (Global System for Mobile communications Association), this category of mobile phones can be sold legally in China.

Since the commercial mobile tele-communication networks established in 1987, there are a great many smuggled mobile phones in China all the time due to the special consumption structure and high tax rate. The sales data of smuggled mobile phones are excluding from the official statistical data, it is estimated to be $10-30 \%$ of the legal mobile phones, even $50 \%$. In addition, MediaTek Inc., a leading fabless semiconductor company for wireless communications and digital multimedia solutions, released the "Turn-key mode" in 2004 to provide the total solution for the manufacturers of mobile phones. The mode, which integrated the chips, operation system platform and third party applications, simplified the manufacturing processes greatly and reduced the access standard of the manufacturing of mobile phones. As a result of this innovation, there are another category of mobile phones that excluding from the official statistical data emerged, which called ShanZhaiShouji in Chinese. The ShanZhaiShouji, which with repeated or false IMEI, usually have no quality assurance from their unregistered manufacturer, so we defined them as counterfeit mobile phones. The industry of counterfeit mobile phones developed rapidly and reached the annual production of 200 million in a few years. The counterfeit mobile phones spread widely, from rural area in China to the low income third world countries. Also, the export is illegal.

The neglect of smuggled and counterfeit mobile phones can lead to significant discrepancy in the estimation, so we need to include the amount of smuggled and counterfeit mobile phones in the sales data. There is no valid sales data of smuggled and counterfeit mobile phones in China, so a questionnaire was designed to assess the citizens' behavior about their use and disposal of mobile phones. The survey was conducted between March and April 2012, promoted both online (at http://www.sojump. com/jq/1370980.aspx) and offline (at Shanghai, Baoding, Baise et al.). The survey was accessed to the respondents with all the careers and age groups in China (including China mainland, Hong Kong, Macao and Taiwan). A total of 5160 complete questionnaires were responded. The results of the survey show that, in the most recent retired mobile phones by the respondents, the legal mobile phones account for $80.42 \%$, the smuggled mobile phones account for $12.06 \%$ and the counterfeit mobile phones account for $7.52 \%$. We can conjecture the sales data of smuggled and counterfeit mobile phones approximate $15 \%$ and $10 \%$ of the sales data of legal mobile phones in the same period, respectively. So we can revise the annual sales data with the following equation:

$S_{t}^{\prime}=S_{t}+S_{t}^{S}+S_{t}^{C}$

where $S_{t}^{\prime}$ is the revised annual sales data; $S_{\mathrm{t}}$ is the annual sales data calculated from the official statistics data; $S_{t}^{S}$ is the estimated annual sales data of smuggled mobile phones; $S_{t}^{\mathrm{C}}$ is the estimated annual sales data of counterfeit mobile phones.

\subsubsection{Lifetime and distribution}

In most of the aforementioned approaches, lifetime of EEE is essential information for the estimation. There are two approaches to estimate the lifetime of commodity. One is the non-parametric approach, which does not assume any statistical distribution. The other one is the parametric approach, which assumes a statistical distribution function such as normal distribution, log-normal distribution, or Weibull distribution, and then approximates the observed data to the statistical distribution function (Oguchi et al., 2010).

Generally there are four basic methods for lifetime estimation: estimation from the number of discarded products for each lifetime, estimation from the number of products in use for each age of product, estimation from the number of products in use for each age at the beginning and the end of a certain period, estimation from the total number of products in use according to the massbalance principle (Murakami et al., 2010).

In this study, the lifetime and distribution of mobile phones is also based on the survey mentioned above. The result of the survey shows that, the average lifetime of mobile phones in China is 1.9 years, which conforms to the previous studies ( $\mathrm{Mu}$ et al., 2010; Gao and Xu, 2011). There are $30.87 \%$ of all the respondents replace their mobile phones annually, $22.68 \%$ replace in $1-2$ years, $28.11 \%$ replace in $2-3$ years and $18.34 \%$ in 3 years or more. This distribution conforms to the previous studies (Gao et al., 2010). Combine the distribution with the results of the previous studies (Mu et al., 2010; Gao et al., 2010), we estimate that there are $30.00 \%$ of the mobile phones are replaced in 1 year, $25.00 \%$ are replaced in 1-2 years, $25.00 \%$ are replaced in 2-3 years and $20.00 \%$ in 3 years or more. 


\subsubsection{Possession and new}

Time series data on mobile phone subscribers in China are available from the website of MIIT (http://www.miit.gov.cn). The domestic possession of mobile phones in the year $t$ is approximately equivalent to the amount of subscribers of the year $t\left(U_{t}\right)$. The amount of new subscribers of the year $t\left(N_{t}\right)$ can be calculated by deduct the amount of subscribers of the year $t-1\left(U_{t-1}\right)$ from the amount of subscribers of the year $t\left(U_{t}\right)$.

\section{Results}

\subsection{Results of the generation estimation}

The different results come from various methods are based on the same annual sales data $S_{t}^{\prime}$, which is revised based on the annual sales data $S_{t}$ calculated from the official statistics data. The results and the details of data are showed in Table 2.

The amount of retired mobile phones increased with the growing annual sales data. It is estimated there are 625.91 million of mobile phones retired in 2012, compared 52.89 million in 2002 with market supply A method. With consumption and use approach, it is estimated there are 585.35 million of mobile phones retired in 2012, compared 108.74 million in 2002. And with sales\&new method, the results are 739.98 million and 47.92 million respectively.

There are some negative values in the line $W_{t}$, which represent there were not enough of new mobile phones for the demand of new subscribers, so some of the retired mobile phones back to the usage phase with the rapid development of the mobile telecommunication industry. When the mobile phones manufacturers in China reached their design capacities, there were enough brand new mobile phones which can meet all the demand, and then the phenomenon of negative values disappeared drastically and never reappear again.

\subsection{Crosscheck}

Based on the logic of consumption and use approach, it can be deduced that the average lifetime (or replacement period) of mobile phones can be calculated by mobile phone subscribers divided by the amount of mobile phones retired. The lifetime of mobile phones were calculated based on the various series of the estimation results by the different approaches and also showed in Table 2.
$L_{R}, L_{\mathrm{Q}}$ and $L_{\mathrm{W}}$ stand for the average lifetime calculated with the estimation results from market supply A method, consumption and use approach and sales\&new method, respectively. The values of $L_{\mathrm{R}}$ illustrate the descend tendency with the time elapsed. The values of $L_{\mathrm{Q}}$ are constant because in the estimation process with consumption and use approach, the same data of the average lifetime is input into the formula. The values of $L_{\mathrm{W}}$ fluctuate with the growing sales data and fluctuant generation of the retired mobile phones, which conform to the reality of rapid development and instauration market of tele-communication industry in China. This can certify the veracity of the estimation result by the sales\&new method.

\section{Comparative study}

In the previous studies, reference 1 (Yu et al., 2010) and 2 (Gao et al., 2010) estimated the generation of retired mobile phones in China with MFA method and market supply A method, respectively; reference 3 (Liao and Zhang, 2012) made a comparative study based on the estimation results of discarded mobile phones in China using the classic market supply method, time-step method and approximation, respectively.

\subsection{Comparison on the results}

The comparison between different results in this study and reference $1 \& 2$ are showed in Fig. 2 . The details of the results in reference 3 are unavailable makes it absent from the comparison. In all the five groups of the results, the amount of retired mobile phones trend to increase with the time elapsed. The results of this study are remarkable higher than the estimation with the same method in the previous studies. The reasons for the differences lie in the estimations with same method are mainly due to the differences in the annual sales data, which are illustrated in Fig. 3 and partly due to we consider the smuggled and counterfeit mobile phones in this study.

\subsection{Causal analysis}

\subsubsection{Sales}

The calculated annual sales data of mobile phones in China in this study $\left(S_{t}\right)$ is higher than the sales data in reference 1 (Yu et al., 2010) $\left(S_{t}^{1}\right)$, as the details of sales data in each study are showed in Table 3. The two groups of annual sales data of mobile phones $\left(S_{t}\right.$ and $\left.S_{t}^{1}\right)$ are calculated in the same method, while the

Table 2

The details of the data and the results of the estimations of retired mobile phones in China (million units).

\begin{tabular}{|c|c|c|c|c|c|c|c|c|c|c|c|c|}
\hline Year & $S_{t}$ & $S_{t}^{S}$ & $S_{t}^{\mathrm{C}}$ & $S_{t}^{\prime}$ & $R_{t}$ & $U_{i}$ & $N_{i}$ & $Q_{t}$ & $W_{t}$ & $L_{\mathrm{R}}$ & $L_{\mathrm{Q}}$ & $L_{\mathrm{W}}$ \\
\hline 1998 & 9.48 & 1.42 & - & 10.91 & - & 23.86 & - & 12.56 & 0.28 & - & 1.90 & 86.18 \\
\hline 1999 & 21.90 & 3.29 & - & 25.19 & - & 43.24 & 19.38 & 22.76 & 5.81 & - & 1.90 & 7.44 \\
\hline 2000 & 33.13 & 4.97 & - & 38.10 & - & 84.53 & 41.29 & 44.49 & -3.19 & - & 1.90 & -26.47 \\
\hline 2001 & 48.51 & 7.28 & - & 55.79 & 30.25 & 145.22 & 60.69 & 76.43 & -4.90 & 4.80 & 1.90 & -29.63 \\
\hline 2002 & 95.05 & 14.26 & - & 109.31 & 52.89 & 206.61 & 61.39 & 108.74 & 47.92 & 3.91 & 1.90 & 4.31 \\
\hline 2003 & 115.90 & 17.38 & - & 133.28 & 79.36 & 268.69 & 62.08 & 141.42 & 71.20 & 3.39 & 1.90 & 3.77 \\
\hline 2004 & 95.47 & 14.32 & - & 109.79 & 99.34 & 334.82 & 66.13 & 176.22 & 43.66 & 3.37 & 1.90 & 7.67 \\
\hline 2005 & 154.34 & 23.15 & 15.43 & 192.92 & 132.15 & 393.43 & 58.60 & 207.07 & 134.32 & 2.98 & 1.90 & 2.93 \\
\hline 2006 & 119.51 & 17.93 & 11.95 & 149.38 & 145.54 & 461.08 & 67.65 & 242.67 & 81.73 & 3.17 & 1.90 & 5.64 \\
\hline 2007 & 198.99 & 29.85 & 19.90 & 248.74 & 168.26 & 547.29 & 86.20 & 288.05 & 162.54 & 3.25 & 1.90 & 3.37 \\
\hline 2008 & 263.30 & 39.49 & 26.33 & 329.12 & 223.23 & 641.23 & 93.94 & 337.49 & 235.18 & 2.87 & 1.90 & 2.73 \\
\hline 2009 & 262.60 & 39.39 & 26.26 & 328.25 & 254.93 & 747.38 & 106.15 & 393.36 & 222.10 & 2.93 & 1.90 & 3.37 \\
\hline 2010 & 512.08 & 76.81 & 51.21 & 640.10 & 366.99 & 859.00 & 111.62 & 452.11 & 528.48 & 2.34 & 1.90 & 1.63 \\
\hline 2011 & 630.81 & 94.62 & 63.08 & 788.51 & 498.53 & 986.25 & 97.77 & 519.08 & 690.74 & 1.98 & 1.90 & 1.43 \\
\hline 2012 & 692.70 & 103.91 & 69.27 & 865.88 & 625.91 & 1112.16 & 125.90 & 585.35 & 739.98 & 1.78 & 1.90 & 1.50 \\
\hline
\end{tabular}

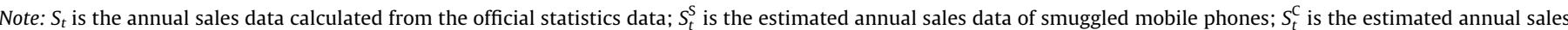

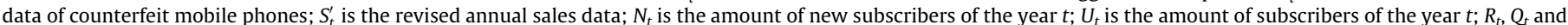

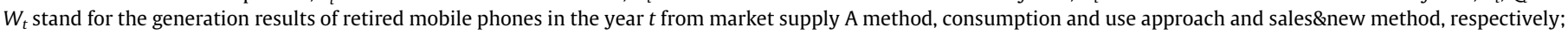

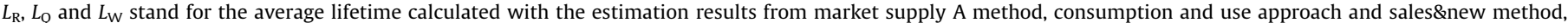
respectively. 


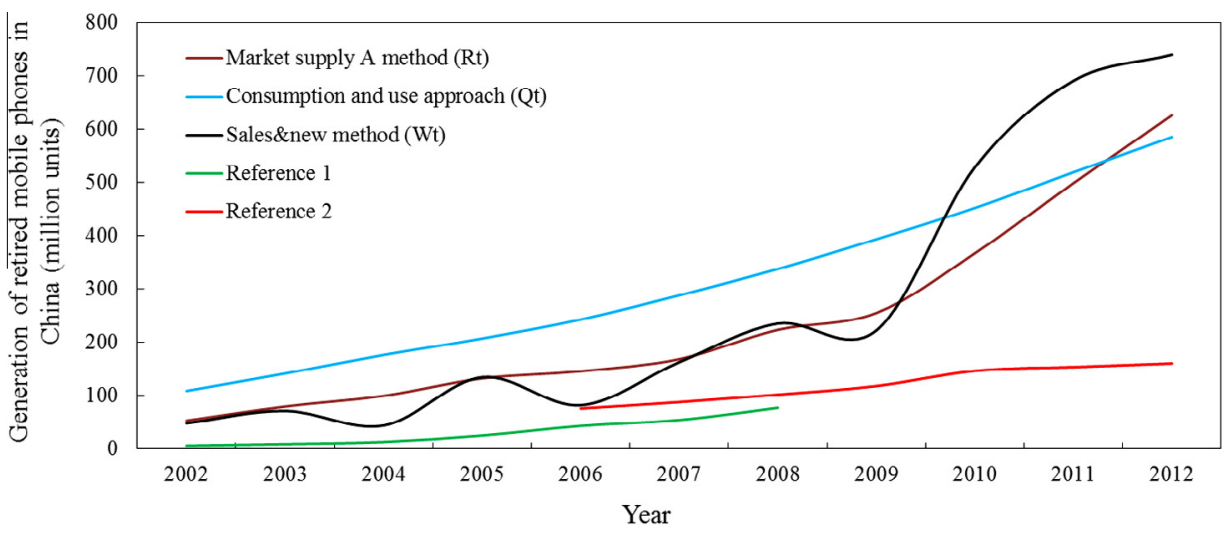

Fig. 2. The comparison between estimation results in different studies.

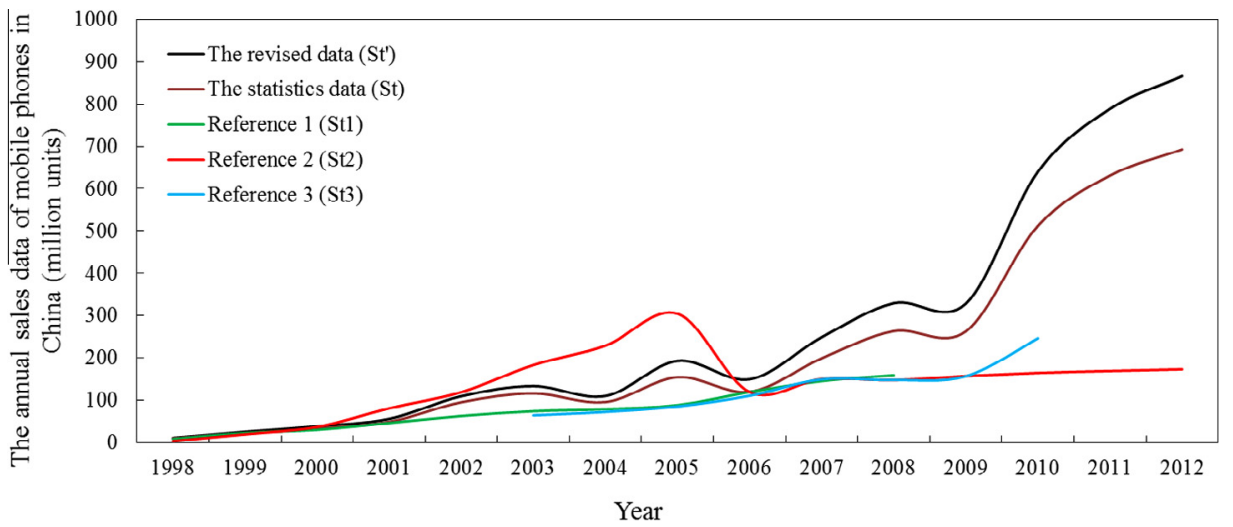

Fig. 3. The comparison between sales data in different studies.

Table 3

The sales data of mobile phones in China in different studies (million units).

\begin{tabular}{|c|c|c|c|c|c|c|c|c|c|c|}
\hline Year & $P_{t}$ & $E_{t}$ & $I_{t}$ & $S_{t}$ & $P_{t}^{1}$ & $E_{t}^{1}$ & $I_{t}^{1}$ & $S_{t}^{1}$ & $S_{t}^{2}$ & $S_{t}^{3}$ \\
\hline 1998 & 8.00 & 0.15 & 1.64 & 9.48 & 8.53 & 0.35 & - & 8.18 & 3.31 & - \\
\hline 1999 & 23.10 & 4.21 & 3.01 & 21.90 & 22.68 & 0.25 & - & 22.43 & 19.15 & - \\
\hline 2000 & 36.64 & 9.51 & 6.00 & 33.13 & 52.48 & 22.75 & - & 29.73 & 36.64 & - \\
\hline 2002 & 118.94 & 41.09 & 17.20 & 95.05 & 108.57 & 63.29 & 17.20 & 62.48 & 118.94 & - \\
\hline 2003 & 183.21 & 89.38 & 22.07 & 115.90 & 147.06 & 95.34 & 22.07 & 73.79 & 183.00 & 64.00 \\
\hline 2004 & 228.79 & 146.05 & 12.72 & 95.47 & 212.02 & 146.05 & 12.72 & 78.69 & 228.79 & 72.00 \\
\hline 2005 & 304.35 & 162.76 & 12.75 & 154.34 & 303.61 & 228.30 & 12.75 & 88.06 & 304.35 & 85.00 \\
\hline 2008 & 559.87 & 314.29 & 17.72 & 263.30 & 560.50 & 533.00 & 17.72 & 159.00 & 147.36 & 147.42 \\
\hline 2009 & 616.39 & 378.26 & 24.47 & 262.60 & - & - & - & - & 157.00 & 156.55 \\
\hline 2010 & 991.36 & 497.93 & 18.65 & 512.08 & - & - & - & - & 164.36 & 246.00 \\
\hline 2011 & 1129.37 & 507.81 & 9.25 & 630.81 & - & - & - & - & 169.06 & - \\
\hline 2012 & 1179.35 & 496.24 & 9.59 & 692.70 & - & - & - & - & 173.04 & - \\
\hline
\end{tabular}

Note: $P_{t}$ and $P_{t}^{1}$ stand for the domestic production of mobile phones in the year $t$ in this study and reference 1, respectively; $E_{t}$ and $E_{t}^{1}$ stand for the amount of export of mobile phones in the year $t$ in this study and reference 1, respectively; $I_{t}$ and $I_{t}^{1}$ stand for the amount of import of mobile phones in the year $t$ in this study and reference 1 , respectively; $S_{t}, S_{t}^{1}, S_{t}^{2}$ and $S_{t}^{3}$ stand for the statistics sales data in the year $t$ in this study and reference $1-3$, respectively.

differences are due to the differences in the related parameters: the domestic production of mobile phones and the amount of export in the year $t$. The two related parameters in reference 1 were derived from a report (Eugster et al., 2007), in which those data have been gathered from various sources. Unfortunately, some data are differing from the official statistics data and there are no words to explain the difference or the correction process. In this study, the parameters are collected from the series of
Electronic Information Industry Statistics Yearbook of China by MIIT, which guarantee the coherence and authority of the data and make the results accurate and authentic. The reference 2 (Gao et al., 2010) confused the domestic production and the sales data of mobile phones, which may lead to the wrong estimation. The sales data in reference 3 (Liao and Zhang, 2012) are cited from the commercial reports by consulting corporations, which have the same issue with reference 1 . 


\subsubsection{Subscribers}

Furthermore, the time series data on mobile phone subscribers in this study are derived from MIIT, the administrative authority. The same data in reference 1 are cited from an international organization called International Tele-communication Union (ITU). There are some differences in the two groups of subscribers data, which may also lead to the discrepancies in the results. In comparison, we consider the data from the administrative authority in China can represent the status quo better.

\subsubsection{Approaches selection}

The selection of estimation approaches can also influence the results directly. For instance, in the previous studies mentioned above, five groups of results based on three groups of sales data and three estimation approaches are provided. All the groups of results are with discrepancies from each other. Unfortunately, no authors of the previous studies can testify the veracity and credibility of the results. So all the estimation results can only illustrate the growth trend of retired mobile phones in China, but cannot provide accuracy information for the sustainable waste management.

\section{Uncertainties analysis}

There is a fundamental assumption in this study: we treat the amount of subscribers as the possession of mobile phones in China. This assumption is based on the following reasons: the possession of mobile phones in China from the official statistics data is always lagging for several years and calculated from the amount of subscribers. Generally speaking, every subscriber in use needs a mobile phone as device, the amount of subscribers can be treated as the whole stock of the mobile phones in use, so the assumption is rational and reasonable. However, there is another source of uncertainties: there are some mobile phones that can put in two or more subscribers in China, which may make the approximate possession tiny bigger than the actuality. This kind of mobile phones can be called Dual-SIM in sum. There are no data about the amount of Dual-SIM available, which make the correction of the possession impossible. Fortunately, the Dual-SIM is minority in the market and possession, so the neglecting is acceptable.

The quantitative process of the sales data of the smuggled and counterfeit mobile phones may be also sources of uncertainties. The combination of survey results and literature data can minimize the error and make the result rational and reasonable.

The quantitative process of lifetime and distribution is sophisticated and difficult to determine, which make the calculated lifetime and distribution to be another source of uncertainties. This condition can also support the approach which is simple in style and has only limited demand of data, the sales\&new method, to be the appropriate choice for the generation estimation of retired mobile phones.

\section{Conclusions}

The priority aim of this paper is to provide reliable generation estimation approach of retired mobile phones on the case study of China. There are already some previous studies on the same topic, the comparison is made between the results in this and previous studies to find out the proper estimation approach. Furthermore, some discussions on methodology are also detailed in order to improve generation estimation of retired mobile phones and other WEEE.

The quantity of retired mobile phones was estimated based on the sales data, amount of the mobile phone subscribers and average lifetime distribution. To make correction to the data, a survey about the use and disposal behavior of the mobile phones users in China is also conducted. Due to the insufficient sources of the data, some assumptions have been made in this study. The sales data of smuggled and counterfeit mobile phones in China are also estimated and involved to provide reliable results. The generation estimations of retired mobile phones in China are launched with three approaches using the same data. After the comparative study on the logic of the approaches and the crosscheck on the estimation results, the sales\&new method is considered to be the proper approach for the generation estimation of the retired mobile phones.

The estimation result of sales\&new method shows that there are 739.98 million mobile phones retired in 2012, compared 47.92 million in 2002. The generation amount of the retired mobile phones in China illustrates an increasing tendency with some fluctuations clearly. The fluctuations are due to the fluctuant values of the sales data and amount of subscribers, which conform to the reality of rapid development and instauration market of telecommunication industry in China. The crosscheck with the calculated average lifetime by mobile phone subscribers divided by the amount of mobile phones retired also testify the veracity of the result with the actually condition. There are some negative values in the result which reflect the special condition in China: there were not enough of new mobile phones for the demand of new subscribers so many retired mobile phones back to the usage phase as a whole unit only with simple maintenance or even not, which also partial lead to the flourish of smuggled mobile phones in China. When the mobile phones manufacturers in China reached their design capacities, there were enough brand new mobile phones which can meet all the demand, and then the phenomenon of negative values disappeared drastically and never reappear again.

The comparative study find out there are more disagreements than agreements among the generation estimation results of retired mobile phones in this paper and previous studies. Discrepancies present even the use of the same input data and approach. The main reasons leading to the discrepancies are the selection of improper approach and error in the input data. It is with great significance to choose the proper approach and reliable data to provide the responsible estimation result for the sustainable management of retired mobile phones and other WEEE.

\section{Acknowledgements}

This research is funded by the Project (Nos. YSW2013B04-03 and 71303231) from the National Natural Science Foundation of China and Research Center for Eco-Environmental Sciences, Chinese Academy of Sciences.

\section{References}

Araujo, M.G. et al., 2012. A model for estimation of potential generation of waste electrical and electronic equipment in Brazil. Waste Manage. 32, 335-342.

California State Congress, 2004. Cell Phone Recycling Act (CPRA). California's Assembly Bill 2091. Sacramento, U.S.

Canning, L., 2006. Rethinking market connections: mobile phone recovery, reuse and recycling in the UK. J. Business Ind. Market. 21, 320-329.

Chi, X.W. et al., 2011. Informal electronic waste recycling: a sector review with special focus on China. Waste Manage. 31, 731-742.

Chung, S.S., 2010. Projecting municipal solid waste: the case of Hong Kong SAR. Resour. Conserv. Recycl. 54, 759-768.

Chung, S.S., 2011. Projection of waste quantities: the case of e-waste of the People's Republic of China. Waste Manage. Res. 30, 1130-1137.

Chung, S.S. et al., 2010. Measuring bulky waste arisings in Hong Kong. Waste Manage. 30, 737-743.

Chung, S.S. et al., 2011. Generation of and control measures for, e-waste in Hong Kong. Waste Manage. 31, 544-554.

Danish Environmental Protection Agency, 2006. A model for projection of ISAG Data, FRIDA

Darby, L., Obara, L., 2005. Household recycling behaviour and attitudes towards the disposal of small electrical and electronic equipment. Resour. Conserv. Recycl. $44,17-35$. 
Dwivedy, M., Mittal, R.K., 2010a. Estimation of future outflows of e-waste in India. Waste Manage. 30, 483-491.

Dwivedy, M., Mittal, R.K., 2010b. Future trends in computer waste generation in India. Waste Manage. 30, 2265-2277.

Environment Bureau, 2010. Safe and sustainable: a new producer responsibility scheme for waste electrical and electronic equipment. Consultation Document, Hong Kong SAR Government, Hong Kong, China.

Eugster, M. et al., 2007. Key environmental impacts of the Chinese EEE Industry. EMPA/Tsinghua University, St. Gallen, Switzerland/Beijing, China.

European Commission, 2012. Directive 2012/19/EU of the European Parliament and of the Council on waste electrical and electronic equipment (WEEE) (recast), Official Journal of the European Union (OJL197/38).

Fishbein, B.K., 2002. Waste in the wireless world: the challenge of cell phones. INFORM Inc., New York, U.S..

Gao, Y.N. et al., 2010. Estimation of waste mobile phones with market supply a method. In: Prce. Annu. Conf. Chin. Soc. Environ. Sci.. Beijing, China, pp. $3597-$ 3601.

Gao, Y.N., Xu, H., 2011. Waste mobile phone recycling in China - based on questionnaires analysis. In: Proceedings of Sixth International Conference on Waste Management and Technology (ICWMT 6). Suzhou, China, pp. 348-355.

Geyer, R., Doctori Blass, V., 2009. The economics of cell phone reuse and recycling. Int. J. Adv. Manuf. Technol. 47, 515-525.

Gutierrez, E. et al., 2010. A competing risks approach for time estimation of household WEEE disposal. Waste Manage. 30, 1643-1652.

Huisman, J. et al., 2007. 2008 review of directive 2002/96 on waste electrical and electronic equipment (WEEE). United Nations University, Bonn, Germany.

International Telecommunication Union (ITU), 2014. The world in 2014: ICT facts and figures. <http://www.itu.int/en/ITU-D/Statistics/Pages/facts/default.aspx> (27.05.14).

Jang, Y.C., Kim, M., 2010. Management of used \& end-of-life mobile phones in Korea: a review. Resour. Conserv. Recycl. 55, 11-19.

Liao, C., Zhang, Y.B., 2012. The estimation study on the amount of discarded mobile phones in mainland China. Ecol. Econ. 250, 124-126 (in Chinese).

Li, J.H. et al., 2006. Status quo of e-waste management in mainland China. J. Mater. Cycles Waste 8, 13-20.

Martinho, G. et al., 2012. Composition of plastics from waste electrical and electronic equipment (WEEE) by direct sampling. Waste Manage. 32, 12131217.

Masui, K., 2005. Calculation of amount of discarded end-of-life products by using multi-regression analysis. In: Fourth International Symposium on Environmentally Conscious Design and Inverse Manufacturing (Eco Design 2005). Tokyo, Japan, pp. 624-625.

Matsuto, T., 2014. A comparison of waste management throughout Asian countries. Waste Manage. 34, 969-970.

Matsuto, T., Tanaka, N., 1993. Data-analysis of daily collection tonnage of residential solid-waste in Japan. Waste. Manage. Res. 11, 333-343.

Ministry of Industry and Information Technology (MIIT), 2003. Electronic Information Industry Statistics Yearbook of China 2002. Publishing House of Electronics Industry, Beijing, China.

Ministry of Industry and Information Technology (MIIT), 2004. Electronic Information Industry Statistics Yearbook of China 2003. Publishing House of Electronics Industry, Beijing, China.

Ministry of Industry and Information Technology (MIIT), 2005. Electronic Information Industry Statistics Yearbook of China 2004. Publishing House of Electronics Industry, Beijing, China.

Ministry of Industry and Information Technology (MIIT), 2006. Electronic Information Industry Statistics Yearbook of China 2005. Publishing House of Electronics Industry, Beijing, China.

Ministry of Industry and Information Technology (MIIT), 2007. Electronic Information Industry Statistics Yearbook of China 2006. Publishing House of Electronics Industry, Beijing, China.

Ministry of Industry and Information Technology (MIIT), 2008. Electronic Information Industry Statistics Yearbook of China 2007. Publishing House of Electronics Industry, Beijing, China.

Ministry of Industry and Information Technology (MIIT), 2009. Electronic Information Industry Statistics Yearbook of China 2008. Publishing House of Electronics Industry, Beijing, China.
Ministry of Industry and Information Technology (MIIT), 2010. Electronic Information Industry Statistics Yearbook of China 2009. Publishing House of Electronics Industry, Beijing, China.

Ministry of Industry and Information Technology (MIIT), 2011. Electronic Information Industry Statistics Yearbook of China 2010. Publishing House of Electronics Industry, Beijing, China.

Ministry of Industry and Information Technology (MIIT), 2012. Electronic Information Industry Statistics Yearbook of China 2011. Publishing House of Electronics Industry, Beijing, China.

Ministry of Industry and Information Technology (MIIT), 2013. Electronic Information Industry Statistics Yearbook of China 2012. Publishing House of Electronics Industry, Beijing, China.

Ministry of Industry and Information Technology (MIIT), 2014. The Telecommunication Industry Operation Condition in January 2014. Beijing China.

Mu, H.S. et al., 2010. The research of innovation management of electronic waste in China which is based on the principle of $3 R$ case study on the management of used mobile phones. In: Proceedings of the Fifth International Conference on Waste Management and Technology (ICWMT 5), Beijing, China, pp. 364-367.

Murakami, S. et al., 2010. Lifespan of commodities, Part I. J. Ind. Ecol. 14, 598-612.

Navarro-Esbri, J. et al., 2002. Time series analysis and forecasting techniques for municipal solid waste management. Resour. Conserv. Recycl. 35, 201-214.

Nnorom, I.C., Osibanjo, O., 2009. Toxicity characterization of waste mobile phone plastics. J. Hazard. Mater. 161, 183-188.

Nokia, 2008. Most Old Mobile Phones are Lying in Drawers at Home and Not Being Recycled. Nokia press bulletin board.

Nordic Council of Ministers, 2009. Method to measure the amount of WEEE generated. Copenhagen, Denmark.

Oguchi, M. et al., 2010. Lifespan of commodities, Part II. J. Ind. Ecol. 14, 613-626.

Ongondo, F.O., Williams, I.D., 2011a. Greening academia: use and disposal of mobile phones among university students. Waste Manage. 31, 1617-1634.

Ongondo, F.O., Williams, I.D., 2011b. Mobile phone collection, reuse and recycling in the UK. Waste Manage. 31, 1307-1315.

Osibanjo, O. et al., 2008. Modelling waste generation by the telecom sector in Nigeria: the grey side of the impressive outing. Waste Manage. Res. 26, $317-$ 326.

Polak, M., Drapalova, L., 2012. Estimation of end of life mobile phones generation: the case study of the Czech Republic. Waste Manage. 32, 1583-1591.

Saphores, J.D. et al., 2009. How much e-waste is there in US basements and attics? Results from a national survey. J. Environ. Manage. 90, 3322-3331.

Silveira, G.T., Chang, S.Y., 2010. Cell phone recycling experiences in the United States and potential recycling options in Brazil. Waste Manage. 30, 2278-2291.

Sole, M. et al., 2012. Proposal of a new model to improve the collection of small WEEE: a pilot project for the recovery and recycling of toys. Waste Manage. Res. 30, 1208-1212.

Statistic Norway, 2004. Projection of organic waste 2001-2020. Notater 2004/38.

Steubing, B. et al., 2010. Assessing computer waste generation in Chile using material flow analysis. Waste Manage. 30, 473-482.

Wagner, T.P., 2009. Shared responsibility for managing electronic waste: a case study of Maine, USA. Waste Manage. 29, 3014-3021.

Walk, W., 2004. Approaches to estimate future quantities of waste electrical and electronic equipment (WEEE). In: Proceedings of the Electronics Goes Green 2004: Driving Forces for Future Electronics, Berlin, Germany, pp. 263-268.

Walk, W., 2009. Forecasting quantities of disused household CRT appliances - a regional case study approach and its application to Baden-Wurttemberg. Waste Manage. 29, 945-951.

Wang, F. et al., 2013. Enhancing e-waste estimates: improving data quality by multivariate input-output analysis. Waste Manage. 33, 2397-2407.

$\mathrm{Wu}$, B.Y. et al., 2008. Assessment of toxicity potential of metallic elements in discarded electronics: a case study of mobile phones in China. J. Environ. Sci China 20, 1403-1408.

Yang, J. et al., 2008. WEEE flow and mitigating measures in China. Waste Manage. $28,1589-1597$

Yoshida, A. et al., 2009. Material flow analysis of used personal computers in Japan. Waste Manage. 29, 1602-1614.

Yu, J. et al., 2010. Analysis of material and energy consumption of mobile phones in China. Energy Policy 38, 4135-4141. 